\title{
Simulation of surface-hoar layers for snow-cover models
}

\author{
Paul M. B. FöHN \\ Swiss Federal Institute for Snow and Avalanche Research, CH-7260 Davos Dorf, Switzerland
}

\begin{abstract}
During two winters, typical meteorological conditions (temperature, humidity, wind, radiation) and snow-surface conditions (snow surface and snow temperatures) were measured to simulate the formation and ablation processes (mainly sublimation) of surface hoar on two level snow plots, situated at 2500 and $1500 \mathrm{~m}$ a.s.l. In order to verify the simulated deposition/ablation rates, the surface-hoar mass, thickness and occasionally density were also measured. The evaluation shows that, using the aerodynamic bulk method for the half-hourly simulation periods, $>90 \%$ of the day/night periods could be rated as either hoar-formation or ablation periods. The simulated sublimation rates (deposition/ablation) deviate in the mean by not more than $10 \%$ from the measured amounts. However, some larger deviations are present, mainly during ablation periods with heavy melting. Finally a method is shown for transforming net deposited vapour amounts into surface-hoar layers of a corresponding height in order to produce "layers" which might be integrated into snowcover simulation models.
\end{abstract}

\section{INTRODUCTION}

The formation and the subsequent embedding of surface-hoar layers in sloping snowpacks is the major cause of thin, weak layers which are extremely important in avalanche release. Whereas the formation process has previously been studied for single nights, there has never been an investigation of how the various processes of both formation and ablation can be simulated. Until now snow-cover models either have not simulated surface-hoar layers or have done so in a crude way with indices, so it was not clear how thick such a layer was and whether it survived over several days until being embedded by new-snow layers.

This paper describes efforts made in the last 2 years to develop a model for daily simulation of surface hoar, which includes the essential physics and is based on simple measurements supplied by automatic snow/weather stations (type Interkantonales Mess- und Informationssystem (IMIS); cf. Fig. 1). This procedure is at present the only way to provide realistic surface-hoar layers for snow-cover models.

Surface hoar is formed at the Earth's surface. It grows by sublimation (deposition) of solid ice crystals directly from water vapour in the air (rime, an occasional variety, is not treated here). Surface hoar forms primarily in the nocturnal air boundary surface layer, in the absence of solar radiation, whenever the snow surface is cooled below the dew-point temperature of the overlying air. This occurs most distinctly when the air humidity is high. Surface-hoar particles, like new-snow particles, have a lattice of crystals, but stay upright, i.e. are ready to collapse, and often take the form of fanshaped, two dimensional crystals, feathery trees, regular plates or slender spikes, depending on the atmospheric conditions.

Knowledge of the importance of surface hoar for avalanche formation has grown only slowly. The practitioner Paulcke (1938) was the first to point out the great importance of surface hoar for avalanche formation. Prob-

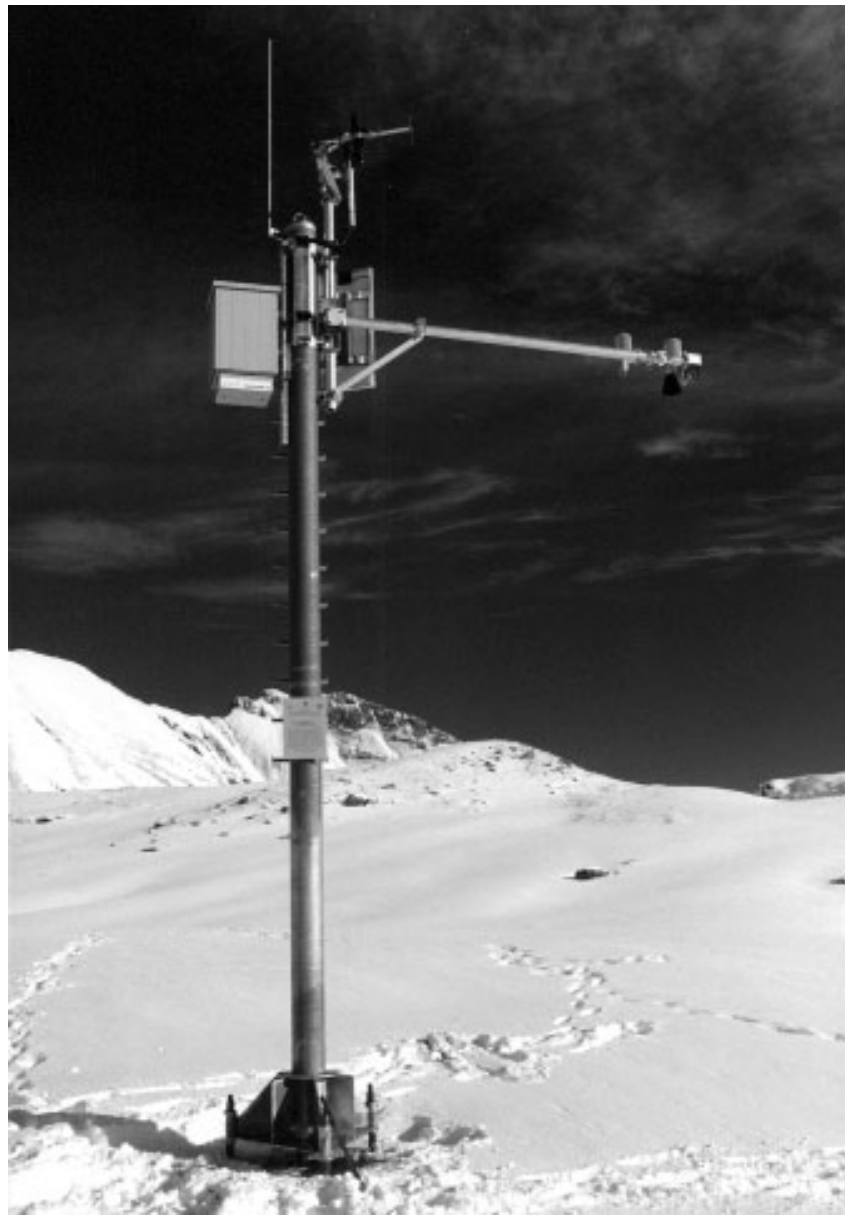

Fig. 1. Remote automatic snow/weather station (IMIS type) measuring air temperature and snow-surface temperature (by infrared sensor), relative humidity, wind speed and direction and snow temperatures at four levels $(0,0.25,0.5,1 \mathrm{~m})$ above ground surface. The snow depth and the reflected shortwave radiation are also measured. 
ably because surface hoar was not a precipitated snow type, it was not included in the first "New classification of dry snow" by Bader and others (1939). For about 20 years, snow and avalanche researchers did not pay much attention to surface hoar, probably because these very thin layers (mmscale) are not easy to recognize during inspections of avalanche fractures, or snow pits, and when seen have often been confused with depth hoar. Until the 1960s, weak snow layer was synonymous with depth-hoar layer. The second explicit reference to surface hoar as an "additional weak layer" was made by Zingg (1966). During the following decades there were a few papers which dealt with surface-hoar formation. Lang and others (1984), Breyfogle (1987) and Colbeck (1988) published details of the growth process. The problem of surface hoar was also described in connection with avalanche formation and with mechanical snow behaviour (Perla, 1975; Föhn, 1993; Föhn and others, 1998). When Colbeck (1987) published a proposal for a new snow-classification system, it contained a section on surface hoar. The international classification for seasonal snow on the ground (Colbeck and others, 1990) integrated this section, thus finally establishing that surface hoar is an important snow layer.

In recent years valuable studies have been made of the special formation characteristics of surface hoar (Hachikubo and Akitaya, 1997, 1998), and the time-dependent behaviour of buried surface hoar has been investigated (Davis and others, 1998; Jamieson and Johnston, 1998; Jamieson and Schweizer, 2000). A special study of forest stands (Höller, 1998) deals with formation in forest clearings. An interesting analysis of the potential of the French snowpack model Crocus with respect to detection of surface-hoar periods has been presented by Mingo and McClung (1998). Gubler (1998) shows ways of simulating the snow-surface characteristics including surface hoar, with indices also relying on remote snow/weather stations.

\section{STUDY AREAS AND MEASUREMENT PROCEDURES}

Surface-hoar deposition and ablation was measured during winters 1997/98 and 1998/99 on two horizontal experimental fields in the mountain region of Davos, Switzerland. The lower field is positioned in the plain of Davos ( $1550 \mathrm{~m}$ a.s.l.), and the upper one on a mountain shoulder below the experimental station Weissfluhjoch ( $9^{\circ} 48^{\prime} 37^{\prime \prime} \mathrm{E}, 46^{\circ} 49^{\prime} 50^{\prime \prime} \mathrm{N}$; $2540 \mathrm{~m}$ a.s.l.). Both positions are also index stations of the official avalanche warning network of Switzerland. Therefore at least once a day the usual snow-cover measurements, including new and total snow depth and snow-surface characteristics (wind-eroded surface, melt crust, surface hoar: yes/no), are observed. Additionally, both fields are equipped with one or several automatic snow/weather stations (type ENET and/or IMIS; for station details see Lehning and others, 1998). These stations measure wind, air temperature and relative humidity at one level, as well as snow depth, snow surface temperature (infrared sensor) and snow temperatures, and the IMIS type also measures the reflected shortwave radiation. Due to the variable snow heights, the meteorological sensors are positioned 4-6 $\mathrm{m}$ above the bare ground. All these sensors are used to simulate the surface-hoar formation and ablation.

Whenever, based on actual weather and meteorological forecasts, a surface-hoar period (deposition/ablation) was expected, additional, detailed surface-hoar measurements were started in both study areas to verify the simulations.
By using two lightweight, rectangular white plastic pans $(0.48 \mathrm{~m} \times 0.38 \mathrm{~m} \times 0.12 \mathrm{~m})$, filled with an undisturbed "cake" of surface snow and positioned a few metres apart into the snow cover (flush with the surface), the gain or loss of snow mass was measured manually by an electronic balance twice a day. Each day was divided into two measuring periods:

(a) A $16 \mathrm{~h}$ night period (potential deposition of hoar) from roughly $1600 \mathrm{~h}$ to $0800 \mathrm{~h}$.

(b) An 8 h day period (likely ablation of hoar) from roughly $0800 \mathrm{~h}$ to $1600 \mathrm{~h}$.

The two relatively long, consecutive periods were chosen because of presence times and the accuracy of the electronic balances $( \pm 0.5 \mathrm{~g})$. As well as these "pan" measurements, measurements of the surface-hoar deposition were also made during these periods using a lightweight, white painted Styrofoam board $(0.5 \mathrm{~m} \times 0.5 \mathrm{~m})$, also set flush with the snow surface, to measure the surface-hoar layer thickness and density and observe the various crystal forms.

\section{THEORETICAL BAGKGROUND OF THE SIMULATION METHOD AND GONDITIONING OF PARAMETERS}

The vapour deposition or sublimation from a snow surface may be calculated by a complete energy balance of the snow surface layers, or measured directly by eddy correlation methods (Morris, 1989) or indirectly by applying an aerodynamic approach. The first method has the disadvantage that such an approach needs, besides accurate radiation measurements, knowledge of surface snow characteristics like liquid-water content, density and thermal conductance, values which are hard to measure on a day-to-day basis. The second method requires expensive and delicate instrumentation. Therefore, only the third method is suitable for this long-term study. Because this work is inspired by the fact that finally only limited data from remote automatic stations are available, the turbulent fluxes are approximated by using meteorological measurements at only one level and transferring the second level into the snow-cover surface, where appropriate and definite boundary conditions may be set more easily, the so-called "bulk approach". The vapourtransfer rate $(E)$ may then be approximated by the following measured or approximated parameters:

$$
E=f\left\{\mathrm{hs}, \rho_{\mathrm{a}}, P_{\mathrm{a}}, u_{z}, T_{\mathrm{s}}, T_{z}, \mathrm{RH}_{z}, z_{0}, \varepsilon\right\},
$$

where hs is the snow height, $\rho_{\mathrm{a}}$ is the air density, $P_{\mathrm{a}}$ is the atmospheric air pressure, $u_{z}$ is the horizontal wind speed at standard height $z, T_{\mathrm{S}}$ and $T_{z}$ are the air temperature at the snow surface and at the standard height $z$, respectively, $\mathrm{RH}_{\mathrm{z}}$ is the relative humidity at standard height $z, z_{0}$ is the snow surface roughness height and $\varepsilon$ is the snow emissivity.

The main parameters are measured within the following accuracy restrictions: $P_{\mathrm{a}}: \pm 0.5 \mathrm{hPa} ; u_{z}: \pm 0.3 \mathrm{~m} \mathrm{~s}^{-1} ; T_{\mathrm{s}}$ : $\pm 0.5^{\circ} ; T_{z}: \pm 1^{\circ} ; \mathrm{RH}_{z}: \pm 5 \%$. Depending on the parameter, the measuring interval varied between 1 and $10 \mathrm{~min}$. For the later simulations half-hourly mean values have been used.

Based on the fact that in near-neutral to moderately stable atmospheric conditions the wind, temperature and humidity profiles above cold surfaces vary approximately logarithmically with height (Fleagle and Businger, 1980), the wind speed measured 3-5 $\mathrm{m}$ above the snow surface (depending on snow depth) and the temperature and humidity values have been transposed to the reference 


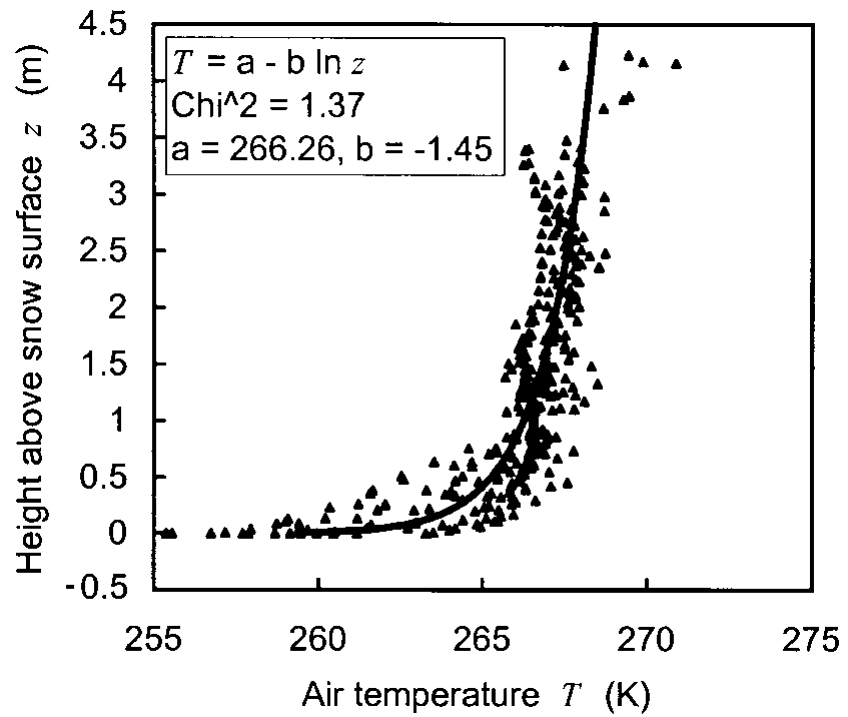

Fig. 2. A collection of air-temperature profiles measured at $0600 \mathrm{~h}$ above a horizontal snow surface at Weissfluhjoch. The profiles were measured during nights with surface-hoar deposition. In order to show the logarithmic course more clearly, the profiles are shifted along the $x$ axis to the mean temperature at a height of $1 \mathrm{~m}$. The profiles of other night hours show a similar trend.

height $1 \mathrm{~m}$ above the snow surface, in order to simulate the moisture flux in the narrow surface layer.

Departing from the well-known wind-profile equation for neutral or near-neutral stability, the wind profile is usually written

$$
u=u_{*} / k\left[\ln \left(z / z_{0}\right)\right], \quad z \geq z_{0},
$$

where $k$ is the von Kármán constant with a value of 0.4 , and $u_{*}$ is the friction velocity. So one may also formulate for the wind speed $u\left(z_{1}\right)$ at $1 \mathrm{~m}$, based on a logarithmic profile shape and adjusted for the daily snow surface height:

$$
u\left(z_{1}\right)=u\left(z_{2}\right) \ln \left[z_{1} / z_{0}\right] /\left[\ln \left(z_{2}-\mathrm{hs}\right) / z_{0}\right],
$$

where hs is the snow height of the snowpack below the automatic station. The height $z_{1}$ is the new reference height at $1 \mathrm{~m}$ and $z_{2}$ is the "old" standard height of sensors as described before. By analogy, the temperature and the relative humidity have also been determined at $1 \mathrm{~m}$ above snow surface.

In order to validate the assumed near-logarithmic course of the temperature profiles, at least during the night-time periods with surface-hoar deposition, detailed air-temperature measurements from a previous winter (Bader and Weilenmann, 1992) have been re-analyzed. The four lowest temperature sensors above snow surface were only $50 \mathrm{~mm}$ apart, and this small-scale temperature chain could be elongated up to $4 \mathrm{~m}$ above snow surface by coupling it with another adjacent temperature-measuring system. Figure 2 shows nearlogarithmic air-temperature profiles measured during surfacehoar deposition nights at $0600 \mathrm{~h}$. (Similar profile shapes have been measured during other night periods.) In order to visualize more clearly the general profile shape, all temperature profiles have been merged at $1 \mathrm{~m}$. The correlation coefficient of the fitted logarithmic curve is reasonable $(R=0.87)$ despite the various temperature-sensor types used to establish these temperature profiles.

\section{SIMULATION OF SURFACE-HOAR LAYERS}

The transfer of water vapour to and away from the snowcover surface has been simulated by the aerodynamic bulk method, which is based on the fact that the most important parameters, namely, the vertical gradients of air temperature, moisture and wind, are often quasi-steady and similar (e.g. Stull, 1988).

Departing from the turbulent flux equation of water vapour $(E)$ may be approximated by

$$
E= \pm K_{\mathrm{e}}\left(0.622 \rho_{\mathrm{a}} / P_{\mathrm{a}}\right) \mathrm{d} e / \mathrm{d} z,
$$

where $K_{\mathrm{e}}$ is the turbulent vapour-transfer coefficient and $\mathrm{d} e / \mathrm{d} z$ is the water-vapour pressure gradient. The plus sign means deposition, and the minus sign ablation by sublimation.

Using the principle of similarity between the turbulent fluxes of latent heat, sensible heat and momentum transfer, valid in near-neutral or moderately stable conditions (Paterson, 1994), one obtains for the turbulent vapour-transfer coefficient $K_{\mathrm{e}}$ the following expression:

$$
\underline{K}_{\underline{e}} \approx K_{\mathrm{h}} \approx K_{\mathrm{m}}=u_{*} k z .
$$

Replacing the new expression for $K_{\mathrm{e}}$ in Equation (4), integrating and replacing $u_{*}$ by Equation (2), the following equation is derived:

$$
E=\left(0.622 \rho_{\mathrm{a}} / P_{\mathrm{a}}\right) u_{z}\left(e_{z}-e_{\mathrm{S}}\right) \underbrace{\left\{k^{2} /\left[\ln \left(z / z_{0}\right)\right]^{2}\right\}}_{C_{\mathrm{e}}},
$$

where the new term above the brace represents a dimensionless parameter $C_{\mathrm{e}}$, the so-called bulk transfer coefficient.

The vapour-pressure difference may be determined by

$$
e_{z}=e_{\mathrm{s}}=\mathrm{RH}_{z} / 100\left[e_{\mathrm{i}}\left(T_{z}\right)-e_{\mathrm{i}}\left(T_{\mathrm{s}}\right)\right],
$$

where $\mathrm{RH}_{z}$ is the relative humidity at reference height $z, e_{\mathrm{i}}$ is the water-vapour pressure at saturation over an ice surface, $e_{\mathrm{i}}\left(T_{z}\right)$ is the saturation vapour pressure based on the approximated air temperature at height $z$, and $e_{\mathrm{i}}\left(T_{\mathrm{S}}\right)$ is the saturation vapour pressure based on the measured snow-surface temperature $T_{\mathrm{s}}$.

The saturation vapour pressure with respect to ice can be calculated with the established Goff-Gratch formulation (List, 1971):

$$
\begin{aligned}
e_{\mathrm{i}}(T) & =\exp \left[-9.1\left(T_{0} / T-1\right)-3.57 \log \left(T_{0} / T\right)\right. \\
& \left.+0.88\left(1-T / T_{0}\right)+\log e_{\mathrm{i} 0}\right]
\end{aligned}
$$

where $T_{0}=273.1 \mathrm{~K}$ and $e_{\mathrm{i} 0}=6.11 \mathrm{hPa}$.

The density of air is calculated by

$$
\rho_{\mathrm{a}} \approx P_{\mathrm{a}} / R T[(1+r) /(1+r / 0.622)],
$$

where $R$ is the gas constant, $T$ is the absolute air temperature and $r$ is the mixing ratio of water vapour to dry air. The mixing ratio $r$ may be calculated by the relative humidity $\mathrm{RH}_{z}$ and by the saturation mixing ratio with respect to ice $\left(r_{\mathrm{i}}\right)$ :

$$
r \approx r_{\mathrm{i}} \mathrm{RH}_{z} / 100 \text {. }
$$

The saturation mixing ratio is

$$
r_{\mathrm{i}} \approx 0.622 e_{\mathrm{i}} /\left(P_{\mathrm{a}}-e_{\mathrm{i}}\right) .
$$

Finally, the bulk vapour-transfer coefficient $C_{\mathrm{e}}$ must be discussed and approximated. The last part of Equation (6) above the brace equals the bulk vapour-transfer coefficient $C_{\mathrm{e}}$ if all previous assumptions (near-neutral conditions, minor local topography effects, rather low winds) are valid:

$$
C_{\mathrm{e}}=k^{2} /\left[\ln \left(z / z_{0}\right)\right]^{2} .
$$

Using a constant reference height $z_{1}$ and using appropriate 


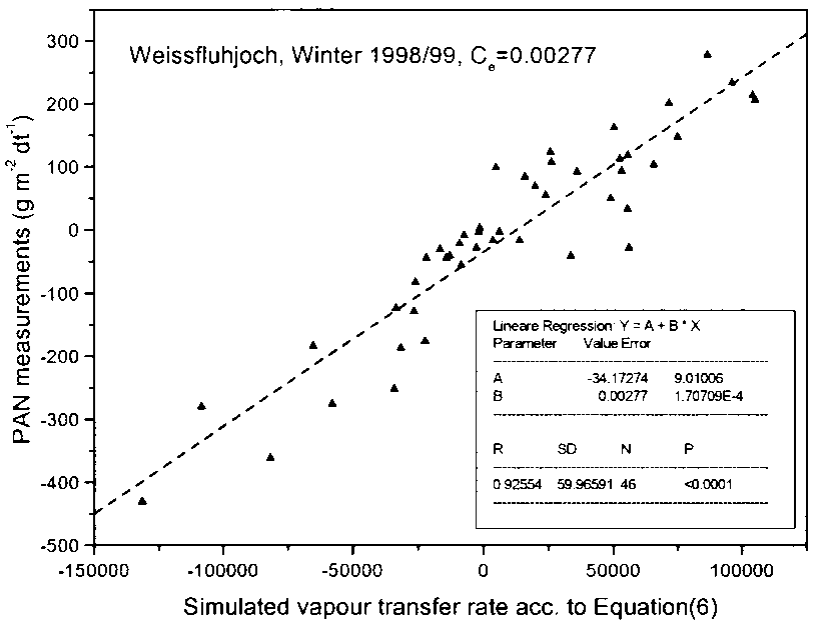

Fig. 3. The linear regression equation line established by regressing the measured sublimation rates of one winter (1998/99) from Weissfluhjoch against the simulated rates in order to determine the bulk vapour-transfer coefficient $C_{\mathrm{e}}$.

$z_{0}$ values, the vapour-transfer coefficient $C_{\mathrm{e}}$ may be approximated. Paterson (1994) published bulk vapourtransfer coefficients in the range $1.5-3.9 \times 10^{-3}$ for melting snow or ice surfaces, collecting data with reference heights 1-2 $\mathrm{m}$ above the snow surface. Hachikubo and Akitaya (1997) determined a mean value of $C_{\mathrm{e}}$ during surface-hoar periods of $2.9 \times 10^{-3}$ for a reference height of $1 \mathrm{~m}$.

From earlier studies also executed in the experimental area Weissfluhjoch, empirical values of the roughness length $z_{0}$ are available: $4 \times 10^{-5} \leq z_{0} \leq 4 \times 10^{-3} \mathrm{~m}$, mean value $1.4 \times 10^{-3} \mathrm{~m}$ (Föhn, 1980); or from a later study (Plüss and Mazzoni, 1994), measuring only under neutral conditions, $2 \times 10^{-5} \leq z_{0} \leq 3 \times 10^{-3} \mathrm{~m}$. Evaluating the above $z_{0}$ values, it has been assumed that the appropriate value of $z_{0}$ would be in the range $0.1 \times 10^{-3}$ to $1.5 \times 10^{-3} \mathrm{~m}$. The rather wide range of $z_{0}$ values is probably due to the fact that during these various studies quite different surface characteristics (fine-grained sun crust, e.g. "firn spiegel", "toothed" surface hoar or coarse wind-driven snow surfaces) were present. Because the present study is primarily concerned with atmospheric situations with high pressure and/or surface-hoar sublimation, it is appropriate to derive, by iterative calculations, for the above-mentioned range of $z_{0}$ the therewith linked transfer coefficients $C_{\mathrm{e}}$ (using Equation (12)).

By iterative calculations, varying $z_{0}$ and consequently $C_{\mathrm{e}}$, the best-fitting $C_{\mathrm{e}}$ has been searched by regressing for one winter the measured surface-hoar mass data of Weissfluhjoch against the simulated surface-hoar mass data and then applying this $C_{\mathrm{e}}$ coefficient, for control reasons, to another independent dataset of Davos. Before definitive simulation runs were started, however, the influence of the wind speed on the sublimation rate had to be analyzed, in view of statements in the literature that a precondition for distinct deposition of surface hoar is "only slight horizontal air motion" or "some wind is necessary" or "for optimal hoar deposition $1-2 \mathrm{~ms}^{-1}$ wind speed at $0.1 \mathrm{~m}$ above surface is necessary" (Lang and others, 1984; Colbeck, 1988; Hachikubo and Akitaya, 1997). By iteratively changing in the simulation model the upper wind-speed limit (at which most of the deposition of surface hoar occurs) from 2 to $5 \mathrm{~m} \mathrm{~s}^{-1}$, an upper limit of $3.0 \mathrm{~m} \mathrm{~s}^{-1}$ was found. This is integrated into the model calculations, but only for surface-hoar deposition periods.

Figure 3 shows this linear regression line established by regressing the measured surface-hoar sublimation rates at Weissfluhjoch for winter 1998/99 against the calculated values using Equation (6). Two extreme outliers have been discarded from the dataset. The parameter $B$ of the regression equation $Y=A+B * C$ in Figure 3 is equivalent to the transfer coefficient $C_{\mathrm{e}}$ for this dataset. It amounts to $2.77 \times 10^{-3}(R=0.93)$. The partially dependent dataset of the previous winter, 1997| 98 , gave a $C_{\mathrm{e}}$ of $2.80 \times 10^{-3}(R=0.85)$ for the same location.

Figures 4 and 5 present the comparison between the measured and calculated sublimation rates at Weissfluhjoch and Davos during winter 1998/99 for the two fixed and previously described time intervals $(\mathrm{d} t)$ per day. For the Davos simulations the same bulk transfer coefficient as for

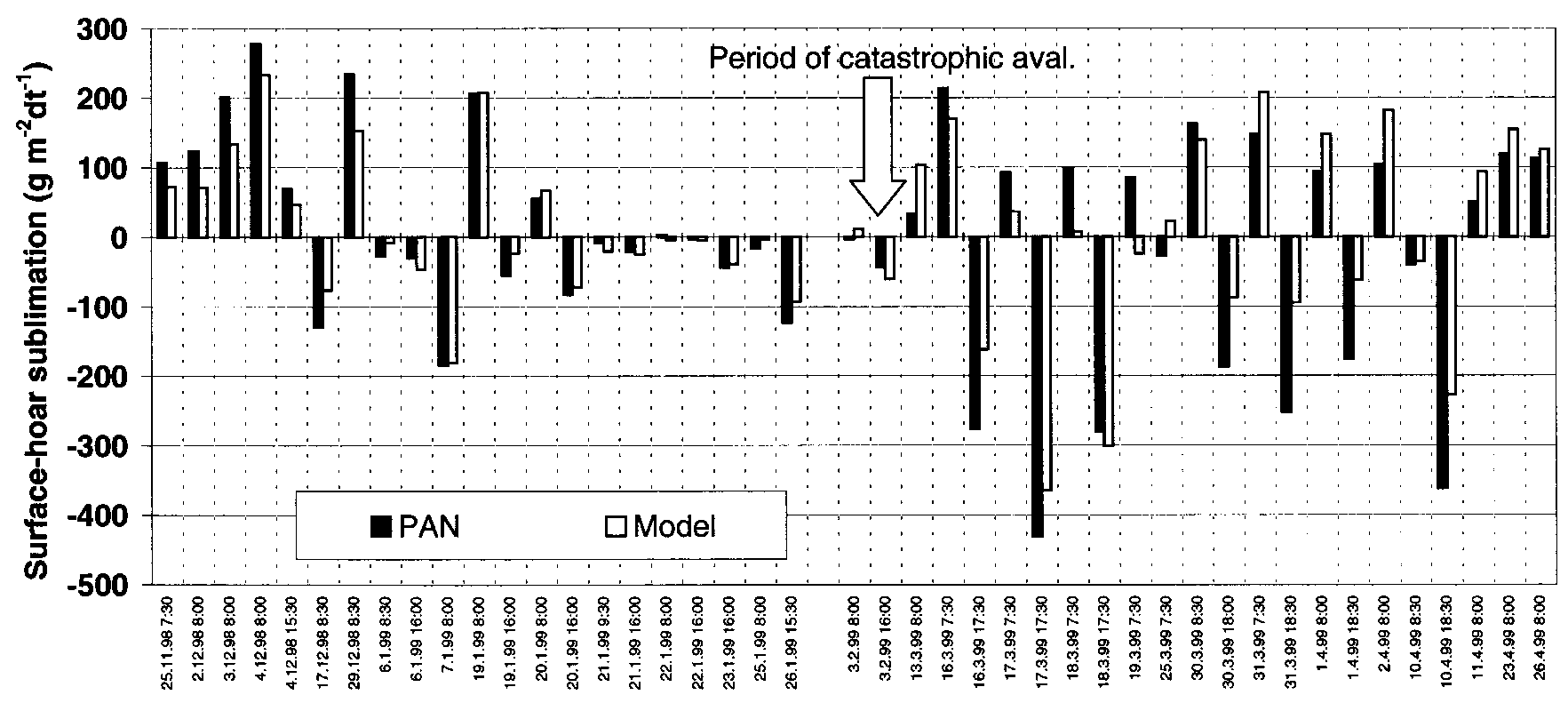

Fig. 4. Visual comparison between measured and simulated sublimation rates at Weissfluhjoch. For the simulation the best-fitting bulk vapour-transfer coefficient $C_{\mathrm{e}}$ of 0.00277 has been adopted. 


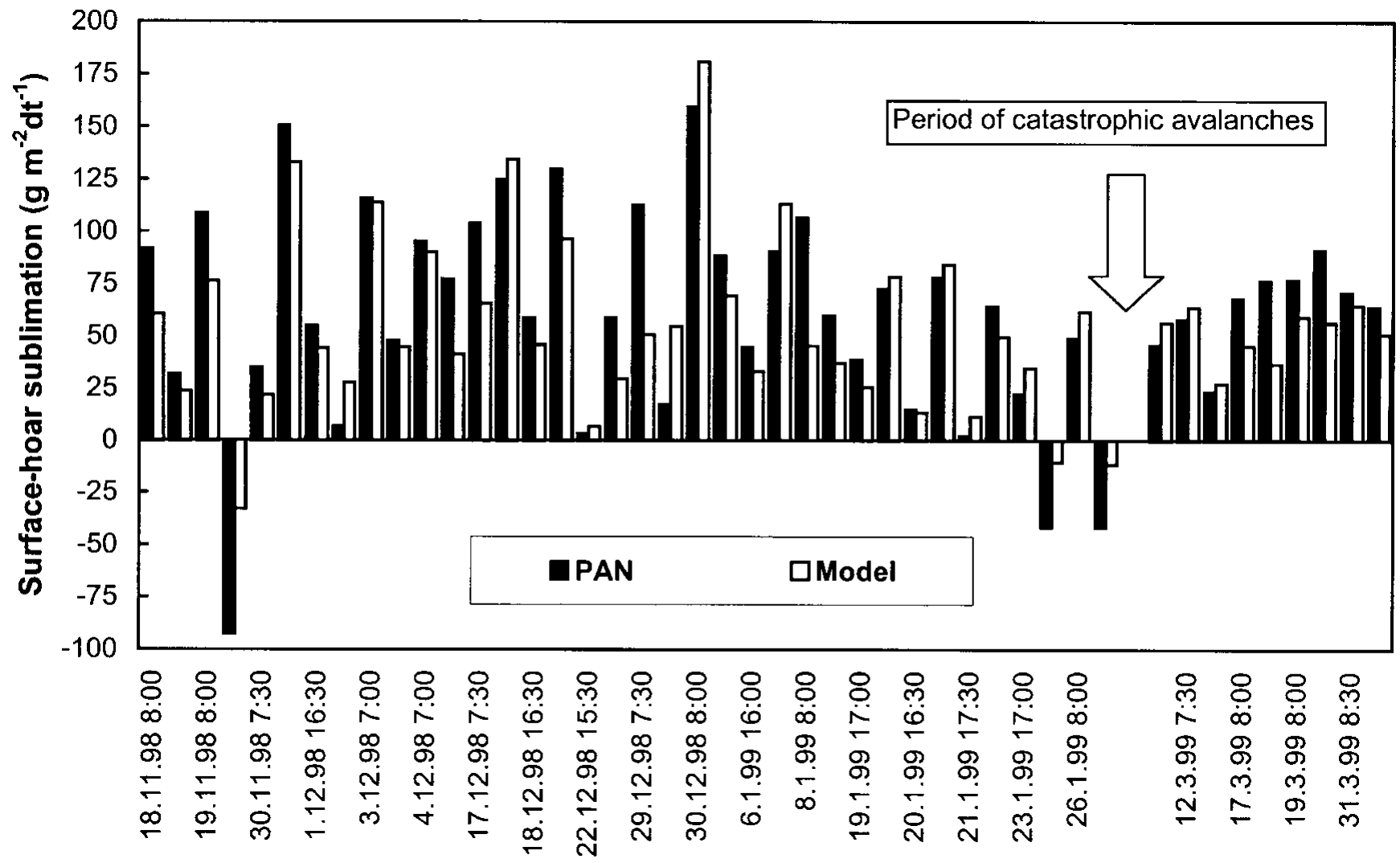

Fig. 5. Visual comparison between measured and simulated sublimation rates at Davos. The bulk vapour-transfer coefficient $C_{\mathrm{e}}$ of 0.00277 , determined from the Weissfluhjoch dataset, has also been used to simulate the sublimation rates at Davos. The concurrence between measured and simulated amounts is still satisfactory, except for the few ablation values.

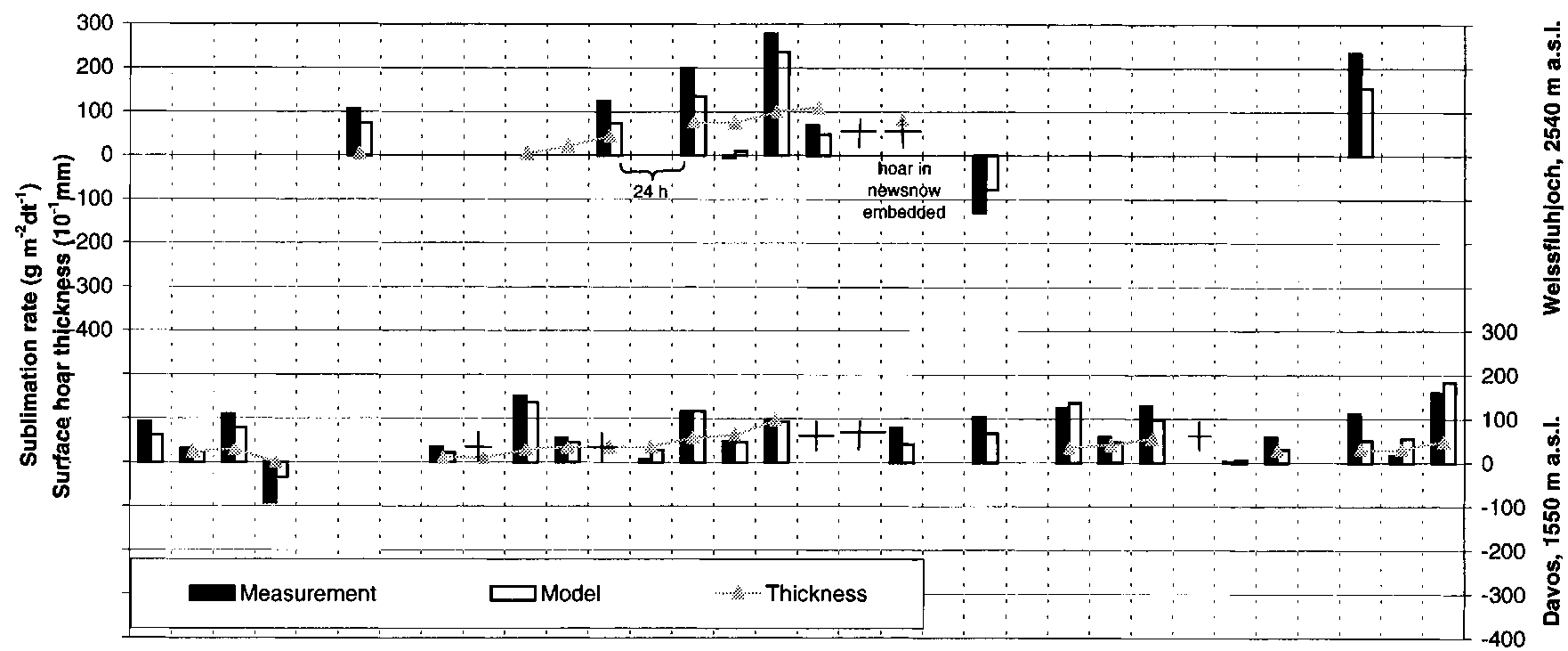

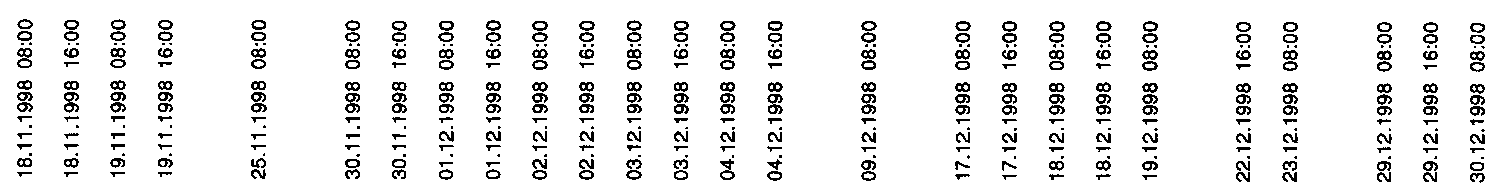

Fig. 6. Parallel representation of measured and simulated sublimation rates and measured surface-hoar layer thickness (heights) at Weissfluhjoch and Davos during the first part of winter 1998/99. Parallel measurements of sublimation rates and surface-hoar layer heights are the clue to translating simulated sublimation rates into realistic surface-hoar layers (thickness, density). 


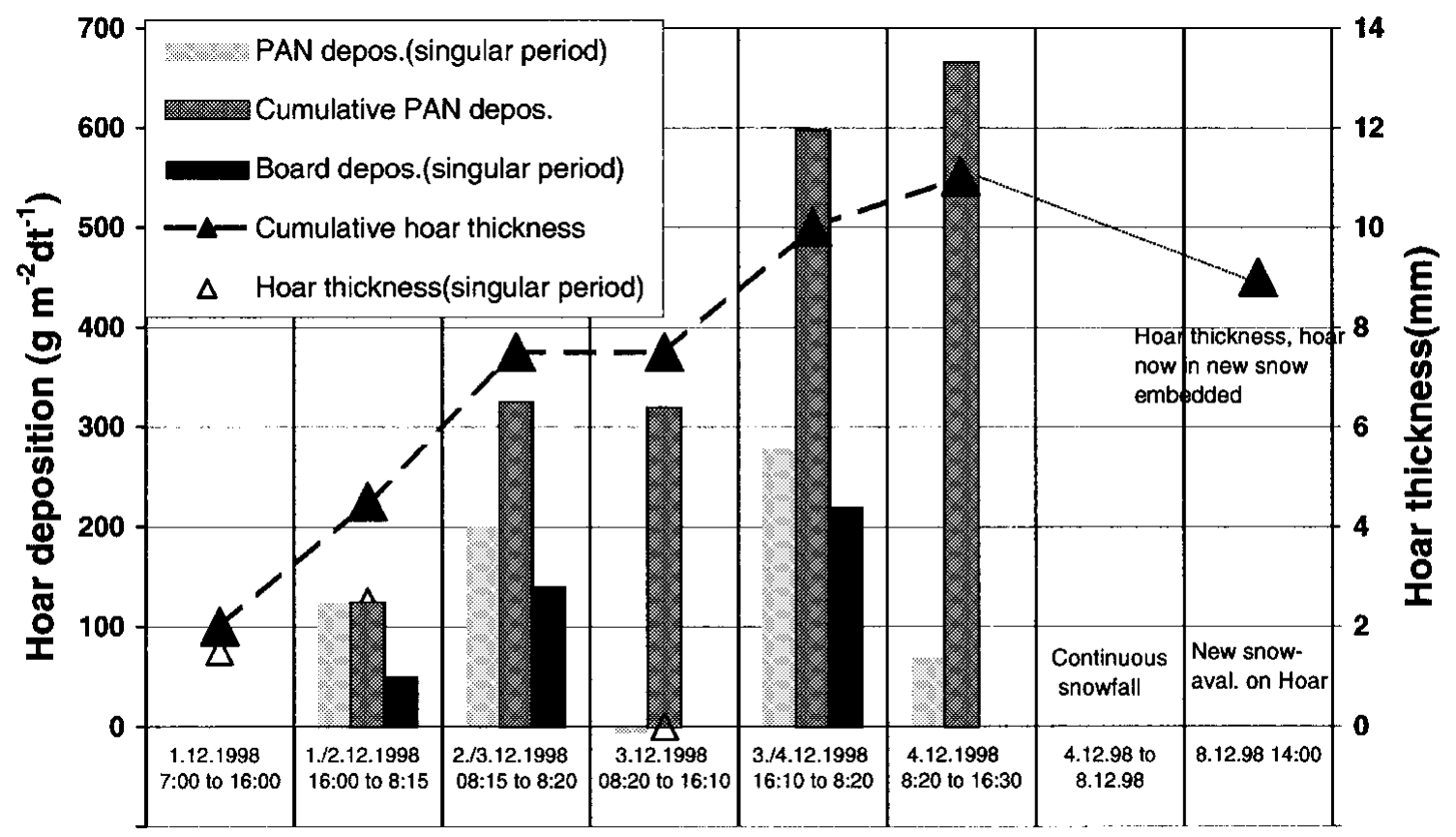

Date, Time

Fig. 7. Detailed representation of all measured and calculated surface-hoar quantities in early December 1998/99 at Weissfluhjoch. The cumulative "pan" deposition values (mosaic columns) follow more or less the course of the cumulative hoar-thickness values (rectangles along the dashed line), but the link between the two (surface-hoar density) cannotyet be clarified sufficiently. The database for these three quantities is still too small.

Weissfluhjoch, $C_{\mathrm{e}}=2.77 \times 10^{-3}$, was tentatively applied, so it was not surprising that the correlation coefficient dropped to $R=0.82$.

Additional iterative calculations for the best-fitted bulk transfer coefficient $C_{\mathrm{e}}$ for the Davos data would yield a value of $2.89 \times 10^{-3}(R=0.85)$.

\section{ANALYSIS AND DISGUSSION OF RESULTS}

Figure 6 yields a comparison of surface-hoar periods between Weissfluhjoch and Davos. It shows on one side the comparison between measured and simulated surface-hoar sublimation amounts from both stations, and on the other side the aspect of deriving from parallel surface-hoar height measurements the layer thickness of surface hoar, which is needed for the snow-cover simulation. Lack of data for a given time interval in the file of one station does not mean that the sublimation process did not occur, but merely that in certain periods the measurements could not be executed in both locations. A cross at a given time interval means that there was snowfall during this period.

The few sublimation periods represented here indicate some facts that are also relevant for other periods observed during winters 1997/98 and 1998/99:

The measured and simulated sublimation amounts, represented by black and white columns, coincide fairly well at both stations, although there is a small tendency, also apparent in Figures 4 and 5, for the modelling procedure to underestimate the measured values.

The ablation process shows this tendency more clearly than the deposition process, which occurs mainly during the night hours. Our measuring procedure, weighing white painted plastic pans which contain the snow-surface "cakes", has the disadvantage that during warm, sunny days the shortwave radiation warms up this "cake", because of artificial wall effects, much more than the free snow surface. So the snow surface temperature within these "cakes" rises faster up to $0^{\circ} \mathrm{C}$, leading to enhanced sublimation (ablation) of water vapour. This tendency is naturally more pronounced at Davos than at Weissfluhjoch. Combining all ablation values from Weissfluhjoch and Davos and calculating the deviations of the modelled values from the measurements (falsified by "surplus heating"), a mean value of $-45 \%$ results. Using Equation (6), and, for all excessive ablation periods, solving it for the vapour pressure $e_{\mathrm{s}}$ by introducing for $E$ the measured "surplus" ablation, the increased vapour pressure and the dependent snow-surface temperature $T_{\mathrm{s}}$ can be determined. The difference $\Delta T_{\mathrm{S}}$ between the undisturbed snow-surface temperature $T_{\mathrm{S}}$ and the disturbed one at the pan surface $T_{\mathrm{s}}$ (pan) amounts to several degrees Celsius per measuring interval. Based on this backtracking, one may assume that the simulated ablation rates are closer to reality, as long as intensive melting periods are not simulated.

The comparison between all measured and simulated sublimation periods at the two locations reveals that Davos experiences surface-hoar deposition periods more often than Weissfluhjoch, but that when surface-hoar deposition occurs at both stations the measured and modelled amount is usually larger at Weissfluhjoch than at Davos. Assuming the same order of magnitude of the water-vapour pressure gradient and the wind speed, this may be due in part to the fact that the $\rho_{\mathrm{a}} / P_{\mathrm{a}}$ ratio and the saturation mixing ratio $r_{\mathrm{i}}$ increases with altitude.

Such tendencies between valley and mountain stations 
suggest that it is not always possible to deduce surfacehoar deposition/ablation in the mountains solely from observations in the valley, and vice versa.

Until now the surface-hoar sublimation has been discussed solely in terms of mass per unit area for a given time interval. However, the conversion of mass into layer units is necessary for a meaningful snow-cover simulation. The comparison between measured mass and thickness values helps to provide a solution.

Figure 6 shows the measured surface-hoar layer thickness parallel to the sublimated mass. If this hoar thickness is measured as mean height of the hoar layer $\left(h_{\mathrm{h}}\right)$, the mass $(M)$ may be approximated for a measuring interval by the well-known relationship

$$
M=\rho_{\mathrm{h}} h_{\mathrm{h}},
$$

where $\rho_{\mathrm{h}}$ represents the surface-hoar density. It is assumed that after several days of continuous sublimation the mass is equivalent to the sum of the consecutive sublimation rates. By finding ways to approximate the surface-hoar density, it is also possible to approximate the surface-hoar thickness based on simulated sublimation rates. There are two ways of approximating the surface-hoar density:

1. Measuring the density of a hoar layer directly in the field whenever a layer of height $h_{\mathrm{h}} \geq 5 \mathrm{~mm}$ has formed. Using a base plate to separate the surface-hoar layer from the lower snowpack and shifting cylinders of 2640-7000 $\mathrm{mm}^{2}$ ground surface vertically onto this layer, a sufficient volume may be obtained and then weighed. This procedure was used in eight surface-hoar situations, and a mean density of $132.4 \mathrm{~kg} \mathrm{~m}^{-3}\left(75<\rho_{\mathrm{h}}<252 \mathrm{~kg} \mathrm{~m}^{-3}\right)$ was found. This value seems rather high given the fluffy, feathery material.

2. Comparing the data of successful parallel measurements of surface-hoar mass (pan measurements) and surfacehoar thickness (board measurements), the density was determined, mainly for surface-hoar layers $<5 \mathrm{~mm}$ high $(N=18)$. The mean density is $102.5 \mathrm{~kg} \mathrm{~m}^{-3}\left(44<\rho_{\mathrm{h}}<215\right.$ $\left.\mathrm{kg} \mathrm{m}^{-3}\right)$. This value seems more appropriate, but is still too high.

Analyzing the data of the second method in more detail, it became clear that the relationship between height (thickness) and accumulated mass is not linear, but exponential. The preliminary data indicate that once the hoar height reaches approximately $1-2 \mathrm{~mm}$, the layer height increases, given the same hoar mass as before, probably because of feedback effects (e.g. enhanced surface roughness $z_{0}$ due to larger surface-hoar crystals). Due to the scarce data, this relationship cannot yet be established. Based on the available measurements, a hoar mean density of $100 \mathrm{~kg} \mathrm{~m}^{-3}$ might be used to approximate the height from simulated sublimation rates.

Figure 7 shows a typical short hoar-formation period in early winter 1998/99, lasting 4 days until the hoar was buried under a 4 day snowfall of roughly $0.3 \mathrm{~m}$ of snow. An interesting detail: as soon as the weather cleared up, many slabs released spontaneously on the buried surface-hoar layer. Represented are the single measurements per interval: pan, board, deposition as specific mass and the hoar thickness on the board. The calculated cumulative pan deposition and the cumulative hoar-thickness values observed on the adjacent snow cover are also presented. Both the hoar thickness and the deposited mass amounts are always smaller on the board than on the pan. These discrepancies are due, first, to the lower "catching power" of the rather smooth board compared with the larger surface roughness of the pan surface which consists of snow and, secondly, to the fact that the initial radiation emissivity of the board is lower than that of a snow surface. The cumulative pan deposition values correspond more or less to the observed hoar-thickness values. If for this short period the daily surface-hoar thickness is approximated by the daily measured pan deposition values (using a density of $100 \mathrm{~kg} \mathrm{~m}^{-3}$ ) and then cumulated, the surface-hoar thickness values are about $20 \%$ lower than the ones measured.

\section{GONCLUSIONS}

The aerodynamic bulk method is the best means of approximating the growth and disappearance of surface-hoar layers, when only limited meteorological data from remote weather/ snow stations are available. However, the occasional wind erosion of such fragile layers must also be included by a coupled snowdrift model. The interval, simulated sublimation rates deviate in the mean by not more than $10 \%$ from the measured amounts. Although the interdependence between surface-hoar thickness and deposited/ablated mass is not yet fully clarified, the simulation procedure presented allows the important layer thickness to be approximated within $20-30 \%$.

Due to the tininess and fragility of surface-hoar crystals it is much more difficult to measure the mean thickness or density of such layers than the sublimation amount deposited or ablated over hours. The model results are to some degree also dependent on the general weather conditions. The model behaves best in typical high-pressure situations, where surface hoar is deposited mainly at night and, due to the rather low air temperatures, daytime ablation is moderate. Where there is intensive warm-air advection, the prevailing ablation is underestimated, because the snow surface is melting $\left(0^{\circ} \mathrm{C}\right)$. For this special situation the heat balance of the uppermost snow-cover layers must also be considered within the framework of existing snow-cover simulation models.

\section{ACKNOWLEDGEMENTS}

I thank O. Bauer, S. Feuerlein, T. Kocher, B. Konantz, G. Krüsi and U. Rieder for their very valuable help with collecting and evaluating the data.

\section{REFERENGES}

Bader, H., R. Haefeli, E. Bucher, J. Neher, O. Eckel and C. Thams. 1939. Der Schnee und seine Metamorphose. Beitr. Geol. Schweiz, Ser. Geotech.Hydrol. 3. (SIPRE Transl. 14, 1954.)

Bader, H.-P. and P. Weilenmann. 1992. Modeling temperature distribution, energy and mass flow in a (phase-changing) snowpack. I. Model and case studies. Cold Reg. Sci. Technol., 20(2), 157-181.

Breyfogle, S. R. 1987. Growth characteristics of hoarfrost with respect to avalanche occurrence. In ISSW'86. A merging of theory and practice. International Snow Science Workshop, 22-25 October 1986, Lake Tahoe, California. Proceedings. Homewood, CA, ISSW Workshop Committee, 216-222.

Colbeck, S. C. 1987. A review of the metamorphism and classification of seasonal snow cover crystals. International Association of Hydrological Sciences Publication 162 (Symposium at Davos 1986 - Avalanche Formation, Movement and Effects), 3-34.

Colbeck, S. C. 1988. On the micrometeorology of surface hoar growth on snow in mountainous area. Boundary-Layer Meteorol., 44(1-2), 1-12.

Colbeck, S. C. and 7 others. 1990. The international classification for seasonal snow on the ground. Wallingford, Oxon, International Association of Scientific 
Hydrology. International Commission on Snow and Ice.

Davis, R. E., B. Jamieson and C. D. Johnston. 1998. Observations on buried surface hoar in British Columbia, Canada - section plane analysis of layer evolution. In ISSW'98. International Snow Science Workshop, 27 September1 October 1998, Sunriver, Oregon. Proceedings. Seattle, WA, Washington State Department of Transportation, 86-92.

Fleagle, R. G. and J. A. Businger. 1980. An introduction to atmospheric physics. New York, Academic Press.

Föhn, P. M. B. 1980. Snow transport over mountain crests. F. Glaciol., 26(94), 469-480.

Föhn, P. M. B. 1993. Characteristics of weak snow layers or interfaces. In Armstrong, R., ed. ISSW'92. A merging of theory and practice. International Snow Science Workshop, 4-8 October 1992, Breckenridge, Colorado. Proceedings. Denver, CO, Avalanche Information Center, 160-170.

Föhn, P. M. B., G. Camponovo and G. Krüsi. 1998. Mechanical and structural properties of weak snow lavers measured in situ. Ann. Glaciol., 26, 1-6.

Gubler, H. 1998. A model to determine snow surface properties from remote measurements. In ISSW'98. International Snow Science Worskhop, 27 September1 October 1998, Sunriver, Oregon. Proceedings. Seattle, WA, Washington State Department of Transportation, 35-48.

Hachikubo, A. and E. Akitaya. 1997. Effect of wind on surface hoar growth on snow. F. Geophys. Res., 102(D4), 4367-4373.

Hachikubo, A. and E. Akitaya. 1998. Daytime preservation of surface-hoar crystals. Ann. Glaciol., 26, 22-26.

Höller, P. 1998. Tentative investigations on surface hoar in mountain forests. Ann. Glaciol., 26, 31-34.

Jamieson, B. and C. Johnston. 1998. Snowpack factors associated with strength changes of buried surface hoar layers. In ISSW'98. International Snow Science Workshop, 27 September-1 October 1998, Sunriver, Oregon. Proceedings. Seattle, WA, Washington State Department of Transportation, 74-85.

Jamieson, J. B. and J. Schweizer. 2000. Texture and strength changes of buried surface-hoar layers with implications for dry snow-slab avalanche release.
7. Glaciol., 46(152), 151-160.

Lang, R. M., B. R. Leo and R. L. Brown. 1984. Observations on the growth process and strength characteristics of surface hoar. In ISSW' 84 . A merging of theory and practice. International Snow Science Workshop, 24-27 October 1984, Aspen, Colorado. Proceedings. Aspen, CO, ISSW Workshop Committee, 188-195.

Lehning, M. and 6 others. 1998. A network of automatic weather and snow stations and supplementary model calculations providing snowpack information for avalanche warning services in Switzerland. In ISSW '98. International Snow Science Workshop, 27 September-1 October 1998, Sunriver, Oregon. Proceedings. Seattle, WA, Washington State Department of Transportation, 188-195.

List, R. J. 1971. Smithsonian meteorological tables. Sixth revised edition. Washington, DC, Smithsonian Institution Press. (Smithsonian Miscellaneous Collections 114$.

Mingo, L. and D. M. McClung. 1998. Crocus test results for snowpack modeling in two snow climates with respect to avalanche forecasting. Ann. Glaciol., 26, 347-356.

Morris, E. M. 1989. Turbulent transfer over snow and ice. F. Hydrol., 105(3-4), 205-223.

Paterson, W. S. B. 1994. The physics of glaciers. Third edition. Oxford, etc., Elsevier.

Paulcke, W. 1938. Praktische Schnee-und Lawinenkunde. Berlin, Julius Springer.

Perla, R. I. 1975. Stress and fracture of snow slabs. International Association of Hydrological Sciences Publication 114 (Symposium at Grindelwald $1974-$ Snow Mechanics), 208-221.

Plüss, C. and R. Mazzoni. 1994. The role of turbulent heat fluxes in the energy balance of high Alpine snow cover. Nord. Hydrol., 25(1-2), 25-38.

Stull, R. B. 1988. An introduction to boundary layer meteorology. Dordrecht, etc., Kluwer Academic Publishers.

Zingg, Th. 1966. Relations between weather situation, snow metamorphism and avalanche activity. International Association of Scientific Hydrology Publication 69 (Symposium at Davos 1965 - Scientific Aspects of Snow and Ice Avalanches), 61-64. 